\title{
Tuning the electronic structure of ultrathin crystalline silica films on $\mathrm{Ru}(0001)$
}

\author{
R. Włodarczyk, M. Sierka, and J. Sauer \\ Institut für Chemie, Humboldt-Universität zu Berlin, Unter den Linden 6, D-10099 Berlin, Germany
}

\author{
D. Löffler, J. J. Uhlrich, X. Yu, B. Yang, I. M. N. Groot, S. Shaikhutdinov, ${ }^{\dagger}$ and H.-J. Freund \\ Department of Chemical Physics, Fritz, Haber Institute of the Max Planck Society, Faradayweg 4-6, D-14195 Berlin, Germany
}

(Received 17 October 2011; revised manuscript received 26 December 2011; published 2 February 2012)

\begin{abstract}
A combination of density functional theory calculations and photoelectron spectroscopy provides new insights into the atomistic picture of ultrathin silica films grown on $\mathrm{Ru}(0001)$. The silica film features a double-layer silicate sheet formed by corner-sharing $\left[\mathrm{SiO}_{4}\right]$ tetrahedra and is weakly bound to the $\mathrm{Ru}(0001)$ substrate. This allows oxygen atoms to reversibly adsorb directly on the metal surface underneath the silica film. We demonstrate that the amount of adsorbed oxygen can be reversibly varied by vacuum annealing and oxidation, which in turn result in gradual changes of the silica/Ru electronic states. This finding opens the possibility for tuning the electronic properties of oxide/metal systems without altering the thickness or the structure of an oxide overlayer.
\end{abstract}

DOI: 10.1103/PhysRevB.85.085403

PACS number(s): 68.35.B-, 68.35.-p, 31.15.A-

\section{INTRODUCTION}

In recent years, thin oxide films have received much interest due to their potential use in many technological applications as insulating layers in integrated circuits, protective films against corrosion, and supports for metal nanoparticles in sensors and catalysts, among other uses. In particular, well-defined ultrathin oxide films grown on metal substrates are excellent systems for studying structure-property relationships, ${ }^{1-6}$ since their electronic and chemical properties can be examined by a variety of surface-sensitive techniques, as well as modern computational methods. ${ }^{7,8}$ The interplay between experimental studies and computer simulations is crucial for understanding the structure and properties of ultrathin oxide films at the atomic level. ${ }^{6-16}$

Silica $\left(\mathrm{SiO}_{2}\right)$ is one of the most important oxides in many modern technologies, with applications ranging from common support material in heterogeneous catalysis to bead for quantum dots ${ }^{17}$ or the backbone of a nanofiltration system. ${ }^{18}$ Beyond native oxide films formed on $\mathrm{Si}$ single crystal substrates, the preparation of thin crystalline $\mathrm{SiO}_{2}$ films has been reported on $\mathrm{Ni}(111),{ }^{19} \mathrm{Pd}(100),{ }^{20} \mathrm{TiO}_{2}(100),{ }^{21}$ and Mo(112). ${ }^{9,22-26}$ For ultrathin crystalline silica films grown on Mo(112) surface, it has been shown that the film is built of a single layer of corner-sharing $\left[\mathrm{SiO}_{4}\right]$ tetrahedra, each bonded to the Mo support by one corner oxygen atom. ${ }^{9,23,24,26}$ In a recent communication, ${ }^{27}$ we reported the first successful preparation of a crystalline silica film on $\mathrm{Ru}(0001)$ that exhibits a two-dimensional network of two layers of corner-sharing $\left[\mathrm{SiO}_{4}\right]$ tetrahedra and is only weakly bound to the metal surface. This structure is a building element of layered silicate minerals (diphyllosilicates) ${ }^{28}$ and can therefore be referred to as a silicate film. Here, we demonstrate that the weak interaction between the oxide film and the metal substrate allows for reversible adsorption of oxygen atoms directly on the metal surface underneath the silica film. The amount of adsorbed oxygen can be varied using vacuum annealing and oxidation, which in turn result in the gradual changes of the silica/Ru electronic states. This allows tuning of the electronic properties of the oxide/metal system without altering the thickness or the structure of the oxide overlayer.
The paper is organized as follows. In Sec. II, we describe the experimental details used for the preparation and characterization of the silica films. The computational methods, a short description of the structural models, and the formalism used to compare the stability of the investigated structures are presented in Sec. III. Experimental and theoretical results are shown in Sec. IV and Sec. V, respectively, which are followed by general discussion in Sec. VI.

\section{EXPERIMENTAL DETAILS}

The experiments were performed in two ultrahigh vacuum (UHV) chambers (base pressures below $5 \times 10^{-10}$ mbar). One chamber was equipped with ultraviolet and x-ray photoelectron spectroscopy (UPS/XPS) using a Scienta SES 200 analyzer, an infrared (IR) spectrometer (Bruker IFS 66v), fourgrid optics for low-energy electron diffraction (LEED, from Omicron), and a scanning tunneling microscope (STM, from Omicron). In addition, electron spectroscopy measurements were carried out at the UE52-PGM beamline at the synchrotron facility BESSY II (Berlin) using a Scienta R4000 analyzer.

The binding energies (BEs) in the $\mathrm{X}$-ray photoelectron (XP) spectra, obtained with the commercial dual x-ray source $\left(h v\left(\mathrm{Mg} \mathrm{K}_{\alpha}\right)=1253.6 \mathrm{eV} ; h v\left(\mathrm{Al} \mathrm{K} \mathrm{K}_{\alpha}\right)=1486.6 \mathrm{eV}\right)$, were referenced to the Fermi edge of a Ru substrate. The photoelectron spectra at BESSY were calibrated with a gold foil by setting the $\mathrm{Au} 4 f_{7 / 2}$ level to $84.0 \mathrm{eV}$ and were obtained at both normal and grazing $\left(80^{\circ}\right)$ electron emissions using photon energies of $200 \mathrm{eV}$ for the $\mathrm{Si} 2 \mathrm{p}$ levels and $630 \mathrm{eV}$ for the O1s levels, respectively.

The $\mathrm{Ru}(0001)$ single crystal $(8 \mathrm{~mm}$ in diameter and $1.5 \mathrm{~mm}$ in thickness, from Mateck) was cleaned by repeated cycles of $\mathrm{Ar}^{+}$sputtering $(2 \mathrm{kV}, 20 \mu \mathrm{A})$ at $500 \mathrm{~K}$ followed by annealing at $1450 \mathrm{~K}$ until no contaminations (typically, carbon and sulfur) were detected by XPS. The temperature was measured by a K-type thermocouple spot welded to the edge of the crystal. In addition, high temperatures were measured by pyrometer for comparison. Due to different sample holder and thermocouple geometries used in these two UHV chambers, there may be some deviations in absolute temperatures used for sample preparations. 
Silicon (99.99\% purity, from Goodfellow) was deposited using an e-beam-assisted evaporator (Focus EFM3). During evaporation, the substrate was biased at the same potential as the Si rod to prevent acceleration of ions toward the sample, which could create uncontrolled defects.

\section{COMPUTATIONAL DETAILS}

All calculations were based on density functional theory (DFT) and were carried out using a Vienna ab initio simulation package (VASP), ${ }^{29,30}$ along with the Perdew-Burke-Ernzerhof $(\mathrm{PBE})^{31,32}$ exchange-correlation functional. The electronion interactions were described by the projector augmented wave method, originally developed by Blöchl ${ }^{33}$ and adapted by Kresse and Joubert. ${ }^{34}$ Only the valence electrons were explicitly considered. A semiempirical dispersion correction was added to qualitatively account for the dispersion forces $(\mathrm{PBE}+\mathrm{D}) \cdot{ }^{35-37}$ Unless stated otherwise, a 400-eV cutoff for the plane wave basis set and a $(8 \times 4 \times 1)$ Monkhorst-Pack grid $^{38}$ for the integrations of the first Brillouin zone were used. The positions of nuclei were relaxed until the forces were smaller than $10^{-3} \mathrm{eV} / \AA$.

The core-level energies were calculated including final state effects using a modified projector augmented wave method. ${ }^{39}$ Harmonic vibrational frequencies were calculated using a central finite difference method with $0.02-\AA$ displacements of the atoms in each Cartesian direction. The intensities were obtained from the derivatives of the dipole moment component perpendicular to the surface. To compensate for systematic errors of DFT, the vibrational frequencies are scaled by an empirical factor of 1.0341 derived from a comparison between experimental ${ }^{40,41}$ and calculated frequencies for $\alpha$-quartz (see Supplemental Material in Ref. 27).

The $\mathrm{Ru}(0001)$ substrate was constructed from a relaxed bulk hexagonal close packed structure with calculated lattice constants of $a=2.698 \AA$ and $c=4.243 \AA$, in excellent agreement with the experimental values of $a=2.696 \AA$ and $c=4.269 \AA .^{42}$ Bulk structure optimization was carried out using a 1200-eV cutoff for the plane wave basis set and a (13 $\times 13 \times 8$ ) Monkhorst-Pack grid ${ }^{38}$ for the integrations of the first Brillouin zone. The surface slabs were modeled using an orthorhombic $(2 \times 2)$ supercell, $a_{0}=5.396 \AA$ and $b_{0}=9.346$ $\AA$, containing five Ru layers, with the three top layers allowed to relax and two bottom layers fixed to their bulk positions.

The stability of different $\left(\mathrm{SiO}_{2}\right)_{8} n \mathrm{O} / \mathrm{Ru}(0001)$ surface models was analyzed using Gibbs free energies of oxygen adsorption, $\Delta G$, according to the reaction

$$
\left(\mathrm{SiO}_{2}\right)_{8} / \mathrm{Ru}(0001)+\frac{n}{2} \mathrm{O}_{2} \rightarrow\left(\mathrm{SiO}_{2}\right)_{8} n \mathrm{O} / \mathrm{Ru}(0001) .
$$

This allows comparison of the stability of the models at different experimental conditions, i.e., oxygen partial pressure and temperature. The adhesion energies of different models, $\Delta E_{\mathrm{adh}}$, were compared according to the equation

$$
\Delta E_{\mathrm{adh}}=E^{\left(\mathrm{SiO}_{2}\right)_{8} n \mathrm{O} / \mathrm{Ru}(0001)}-\left(E^{n \mathrm{O} / \mathrm{Ru}(0001)}+E^{\left(\mathrm{SiO}_{2}\right)_{8}}\right),
$$

where $E^{\left(\mathrm{SiO}_{2}\right)_{8} n \mathrm{O} / \mathrm{Ru}(0001)}$ corresponds to the energy of a given $\left(\mathrm{SiO}_{2}\right)_{8} n \mathrm{O} / \mathrm{Ru}(0001)$ model, $E^{n \mathrm{O} / \mathrm{Ru}(0001)}$ is the energy of the oxygen-covered $\mathrm{Ru}(0001)$ surface, and $E^{\left(\mathrm{SiO}_{2}\right)_{8}}$ is the energy of the isolated silica double layer.

\section{EXPERIMENTAL RESULTS}

The clean $\mathrm{Ru}(0001)$ substrate was first oxidized in $5 \times$ $10^{-8}$ mbar of $\mathrm{O}_{2}$ at $373 \mathrm{~K}$ for $6 \mathrm{~min}$, which resulted in a $(2 \times 1) \mathrm{O} / \mathrm{Ru}(0001)$ structure $^{43,44}$ with an oxygen coverage of $0.5 \mathrm{ML}$. The oxygen ad-layer was used primarily to prevent intermixing of $\mathrm{Si}$ and $\mathrm{Ru}$, as well as to facilitate the oxidation of $\mathrm{Si}$ ad-atoms. Deposition of $\sim 1.2 \mathrm{ML}$ of $\mathrm{Si}$ onto the O-covered $\mathrm{Ru}(0001)$ in $10^{-7}$ mbar of $\mathrm{O}_{2}$ caused disappearance of the LEED pattern, thus indicating a lack of long-range ordering. Indeed, STM inspection revealed a granular-like film with a broad size distribution of particles $\sim 10 \mathrm{~nm}$ in their lateral dimension and $\sim 2 \mathrm{~nm}$ in height, on average (not shown). The XP spectra of this sample (Fig. 1) reveal multiple oxidation states for $\mathrm{Si}$, with most in the $\mathrm{Si}^{4+}$ state $(103.3 \mathrm{eV})$ based on the BEs of silica materials reported in the literature. ${ }^{45-47}$ The rest of $\mathrm{Si}$ (BEs between 99 and $102 \mathrm{eV}$ ) resides nonoxidized or forms suboxides like $\mathrm{Si}_{2} \mathrm{O}, \mathrm{SiO}$, and $\mathrm{Si}_{2} \mathrm{O}_{3}$. The relative intensity of the $\mathrm{Si} 2 \mathrm{p}$ states at low BEs was increasing at higher photon energy and diminishing at grazing emission (not shown), thus suggesting that oxidized Si species dominate the surface.

To prepare a well-ordered film, the silica deposits were further oxidized in $2 \times 10^{-6}$ mbar of $\mathrm{O}_{2}$ at $1140 \mathrm{~K}$ for $15 \mathrm{~min}$. The oxygen was pumped out after the sample cooled down to $\sim 500 \mathrm{~K}$. STM images (not shown) of the resultant surface revealed a flat film covering practically the entire surface with the area of scarce pits and/or holes not exceeding $10 \%$.

The $\mathrm{Si} 2 \mathrm{p}$ region (Fig. 1) revealed the sharp peak centered at $102.5 \mathrm{eV}$ (the full width at half maximum, or FWHM, is $1.35 \mathrm{eV}$ ), indicating the presence of only one oxidation state of $\mathrm{Si}$ in the film. In principle, the obtained BE falls into the range expected for $\mathrm{Si}^{3+}$ and $\mathrm{Si}^{4+}$ compounds. ${ }^{45-47}$ The precise assignment of oxidation states in thin films based on BEs is not straightforward due to the final state effects. The energy separation between the Si2p and the O1s levels (429.2 $\pm 0.2 \mathrm{eV})$ is close to that reported in Ref. 45 for native $\mathrm{SiO}_{2}$ films on Si, i.e., $429.9 \mathrm{eV}$, and is definitely much smaller than reported in the same paper for $\mathrm{Si}_{2} \mathrm{O}_{3}$ and $\mathrm{SiO}$ bulk compounds

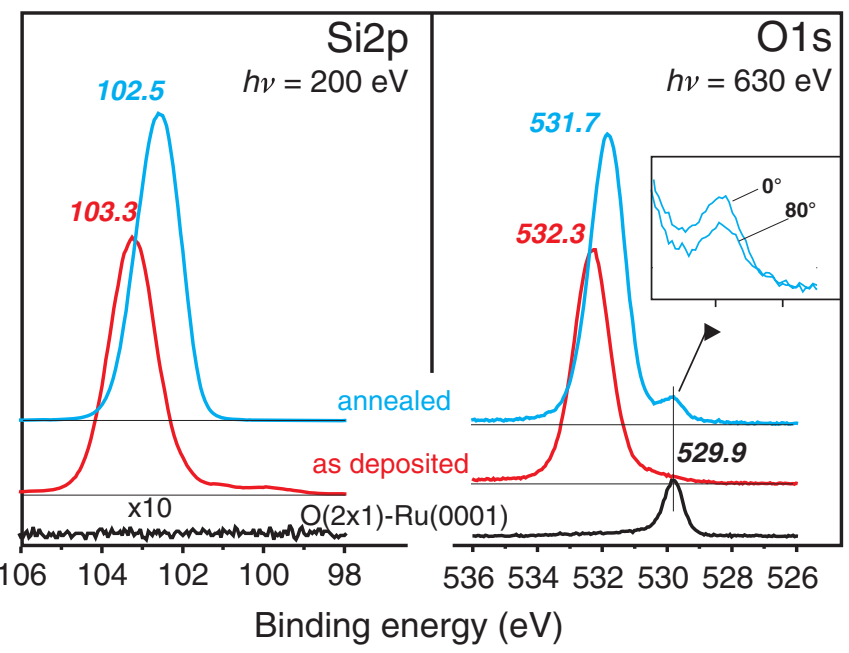

FIG. 1. (Color online) Si2p and O1s regions in the XP spectra of a $\mathrm{SiO}_{2}$ film grown on $\mathrm{Ru}(0001)$ obtained in the course of preparation of a silica film as indicated. 


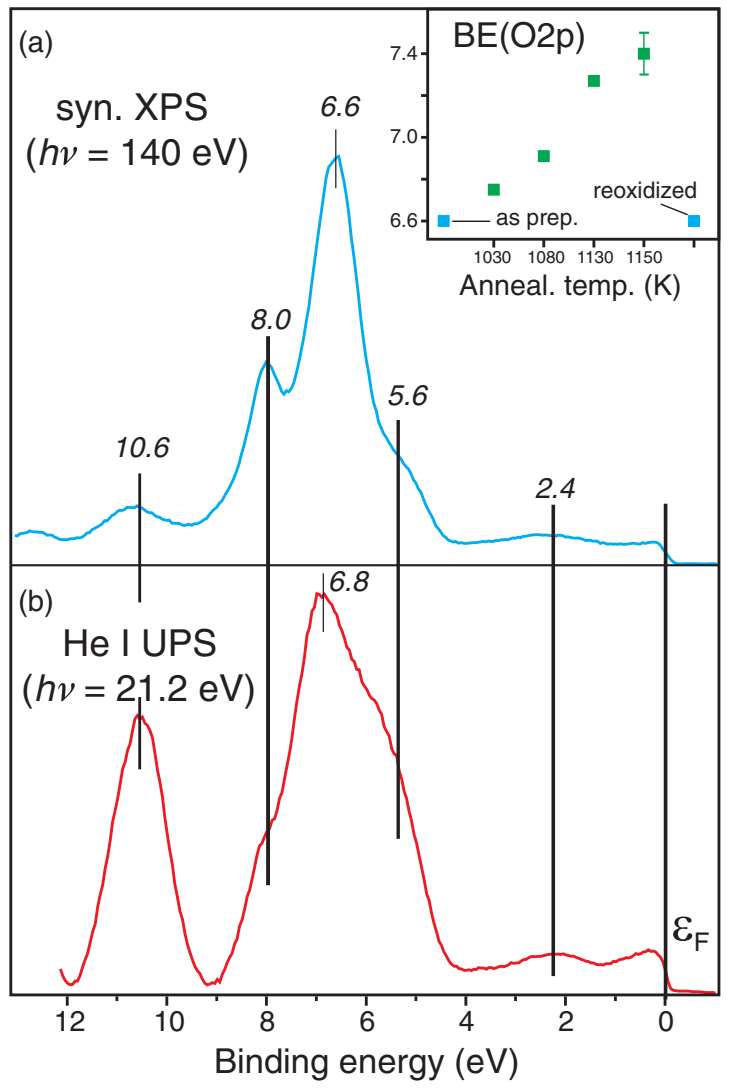

FIG. 2. (Color online) XP spectra of the valence band obtained with (a) synchrotron radiation $(h v=140 \mathrm{eV}$ ) and (b) He I light $(h v=21.2 \mathrm{eV})$ of the as-prepared $\mathrm{SiO}_{2} / \mathrm{Ru}(0001)$ films. The inset shows the peak position of the most intense peak (at $6.6 \mathrm{eV}$ ) as a function of the annealing temperature in UHV.

(432.6 and $432.8 \mathrm{eV}$, respectively). Therefore, we conclude that $\mathrm{Si}$ is present in films solely in a fully oxidized $\mathrm{Si}^{4+}$ state.

The O1s region of the prepared films shows two sharp $(\mathrm{FWHM}=1.3 \mathrm{eV})$ peaks, with an intensity ratio of $\sim 12: 1$. The main peak at $531.7 \mathrm{eV}$ can be attributed straightforwardly to oxygen coordinated to $\mathrm{Si}$ (hereafter referred to as $\mathrm{O}(\mathrm{Si})$ ). The second peak at $529.9 \mathrm{eV}$ has the same $\mathrm{BE}$ as the one measured on the $(2 \times 1) \mathrm{O} / \mathrm{Ru}(0001)$ surface and is therefore assigned to oxygen chemisorbed on the Ru substrate underneath the silica film (referred to as $\mathrm{O}(\mathrm{Ru})$ ). This conclusion was further supported by the attenuation of the $529.9-\mathrm{eV}$ peak at grazing emission (as shown in the inset of Fig. 1), indicating the "subsurface" nature of respective species. Using the $(2 \times$ 1) $\mathrm{O} / \mathrm{Ru}(0001)$ surface as a reference, the absolute amounts of these $\mathrm{O}$ atoms in the samples varies in the range of $0.25-0.5 \mathrm{ML}$, depending on how we take into account the signal attenuation by the top-lying silica layer.

The valence band of the silica films was studied both with ultraviolet light $(h v(\mathrm{He} \mathrm{I})=21.2 \mathrm{eV})$ and with synchrotron radiation $(h v=140 \mathrm{eV})$. Basically, both techniques show the same features (Fig. 2). Small differences between the spectra can be explained by different ionization cross-sections at the photon energies used and a relatively higher spectral resolution obtained with the synchrotron light. The peak $\sim 2.4 \mathrm{eV}$ and the shoulder $\sim 5.6 \mathrm{eV}$ can be assigned to the states

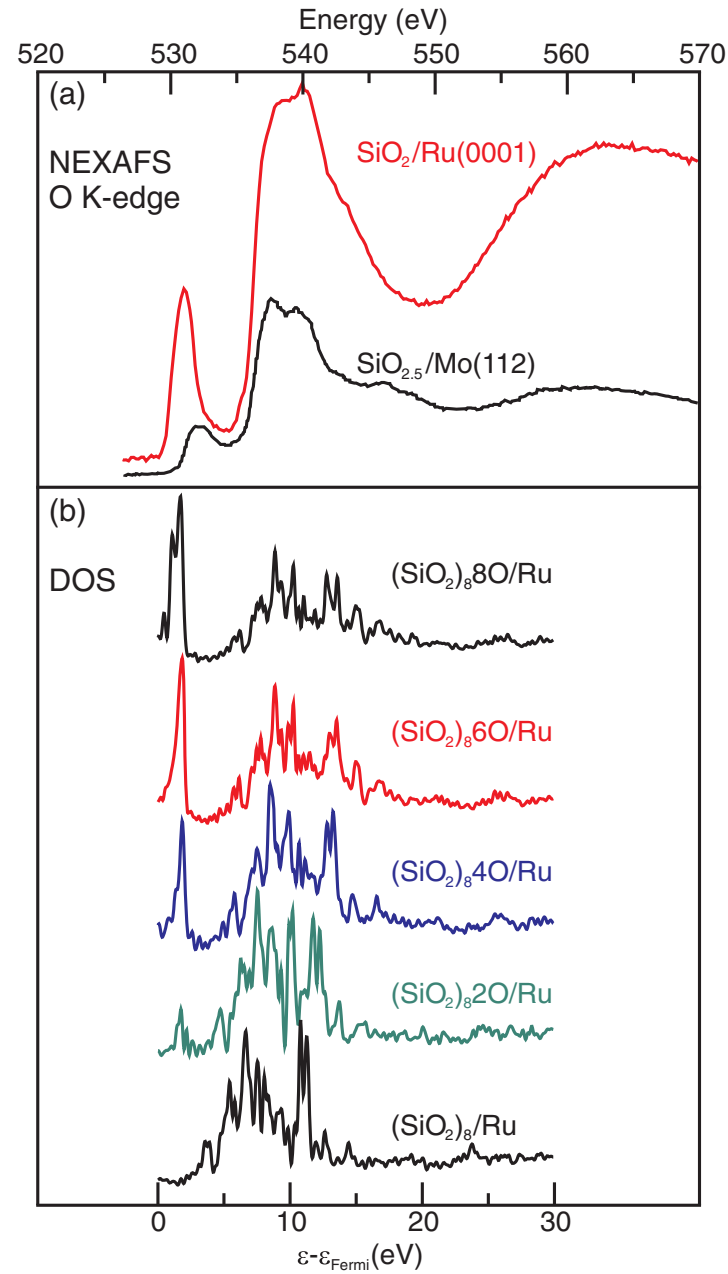

FIG. 3. (Color online) (a) NEXAFS spectrum for the O K-edge of an O-rich $\mathrm{SiO}_{2}$ film on $\mathrm{Ru}(0001)$. The spectrum for a monolayer silica film on Mo(112) is shown for comparison. (b) Calculated density of the unoccupied $\mathrm{O} 2 \mathrm{p}$ states, i.e., states above the Fermi level.

related to the oxygen-covered $\mathrm{Ru}$ substrate. ${ }^{48-50}$ The bands between 5 and $9 \mathrm{eV}$ are attributed to $\mathrm{O} 2 \mathrm{p}$ nonbonding states in silica. ${ }^{24,51-53}$ Overlap of the $\mathrm{O} 2 \mathrm{p}$ nonbonding states from the $\mathrm{O}-\mathrm{Si}$ and the O-Ru bonds, as well as the hardly resolved splitting of the $p_{x}$ and $p_{y}$ orbitals, expected for the silica compounds with a nonlinear Si-O-Si bond configuration, ${ }^{54}$ causes some broadening in this region. The peak $\sim 10.6 \mathrm{eV}$ can be assigned to the hybridized $\mathrm{O} 2 \mathrm{p}-\mathrm{Si} 3 \mathrm{~s}, 3 \mathrm{p}$ bonding orbitals in Si-O-Si building blocks. ${ }^{24,53-55}$ The electronic state $\sim 11.5 \mathrm{eV}$, observed for $\mathrm{SiO}_{2.5}$ films on $\mathrm{Mo}(112),{ }^{24,53}$ is missing here due to the absence of Si-O-Ru bonds in the silicate film grown on $\mathrm{Ru}(0001)$.

Near-edge x-ray absorption fine structure (NEXAFS) spectroscopy also supports the silicate-like structure of the silica films on $\mathrm{Ru}(0001)$. Figure 3(a) shows the spectrum for the $\mathrm{O} \mathrm{K}$-edge, where states with an unoccupied O2p-like character are probed. ${ }^{56}$ This spectrum is characteristic for $\mathrm{Si}$ in tetrahedral $\left[\mathrm{SiO}_{4}\right]$ coordination, like in quartz and $\alpha$ - and $\beta$-cristobalites, which is in turn significantly different from those observed on the compounds with corner- and edge-sharing $\left[\mathrm{SiO}_{6}\right]$ octahedra-e.g., in stishovite. ${ }^{57,58} \mathrm{Not}$ 

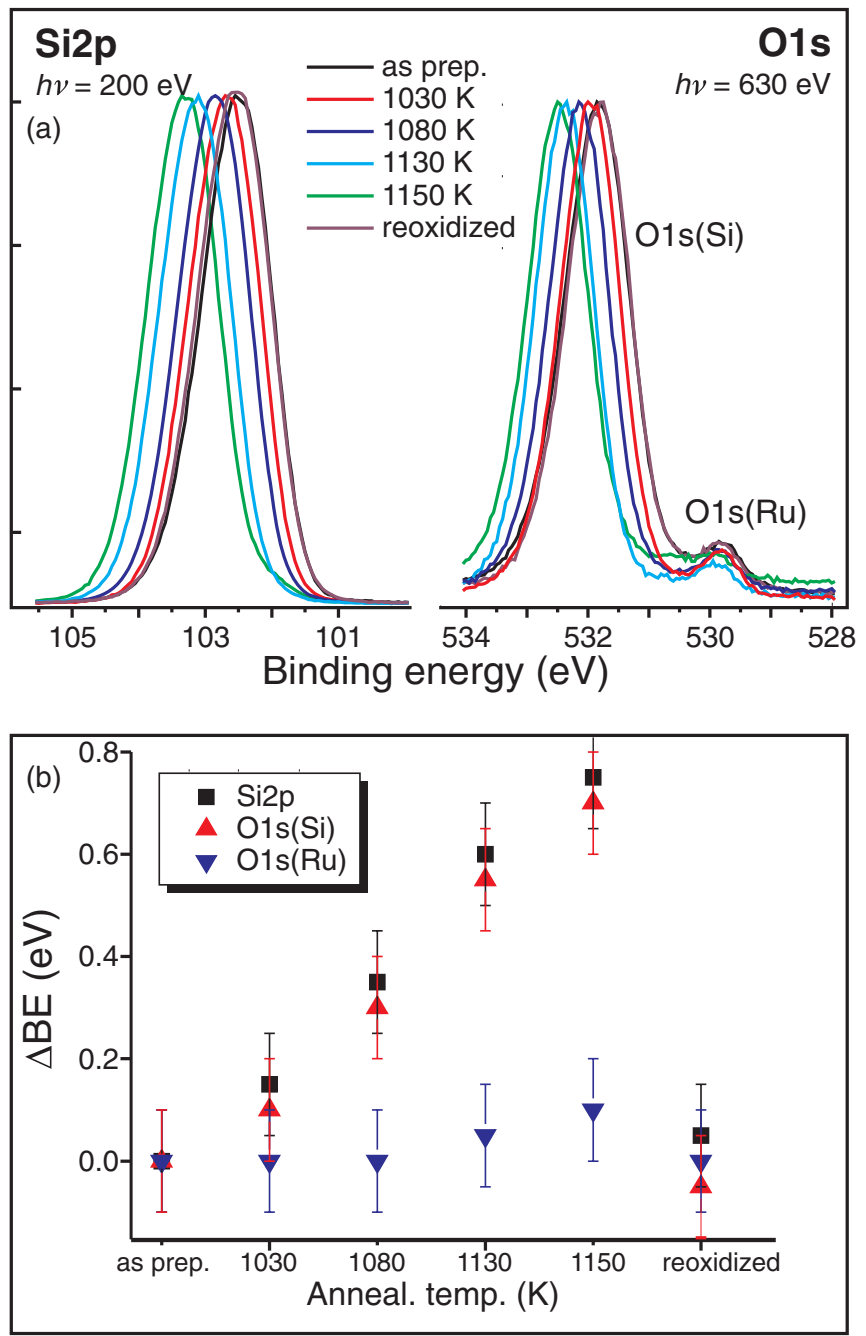

FIG. 4. (Color online) (a) The $\mathrm{Si} 2 \mathrm{p}(h v=200 \mathrm{eV})$ and $\mathrm{O} 1 \mathrm{~s}$ $\left(h v=630 \mathrm{eV}\right.$ ) regions in XP spectra of $\mathrm{SiO}_{2} / \mathrm{Ru}(0001)$ as a function of annealing temperature in UHV as indicated and after sample reoxidation at $1140 \mathrm{~K}$ for $10 \mathrm{~min}$ in $2 \times 10^{-6} \mathrm{mbar}_{2}$. (b) $\mathrm{BE}$ shifts measured from the spectra shown in (a).

surprisingly, the spectrum is similar to that observed for $\mathrm{SiO}_{2.5}$ film on Mo(112) (Ref. 24, shown in Fig. 3(a) for comparison), since both structures exhibit the same structural motif, i.e., corner-sharing $\left[\mathrm{SiO}_{4}\right]$ tetrahedra.

To monitor thermal stability of the films, we performed XPS studies as a function of annealing temperature (Fig. 4). It turned out that the Si2p peak shifts by $\sim 0.8 \mathrm{eV}$ (i.e., from $102.5 \mathrm{eV}$, measured for the "as-prepared" films, to 103.3 eV) upon UHV annealing to $1150 \mathrm{~K}$. A similar shift is observed for the $\mathrm{O} 1 \mathrm{~s}(\mathrm{Si})$ level such that the energy separation between the Si2p and the $\mathrm{O} 1 \mathrm{~s}(\mathrm{Si})$ peaks remains constant. Also, the intensity and FWHM of these two signals are not changed. Therefore, the silica film maintains its chemical composition and stoichiometry. The $\mathrm{O} 1 \mathrm{~s}(\mathrm{Ru})$-related peak does not shift, although the intensity decreases upon UHV annealing to $1150 \mathrm{~K}$ by a factor of approximately two. Interestingly, the BE shifts are observed in the same range of temperatures as the onset of the oxygen desorption on $\mathrm{Ru}(0001) .{ }^{59,60}$ All these findings suggest that during UHV annealing the interfacial oxygen between $\mathrm{SiO}_{2}$ and $\mathrm{Ru}(0001)$ desorbs, ultimately forming so-called O-poor films compared to the as-prepared "O-rich" films, the nomenclature we used for monolayer silica films grown on $\mathrm{Mo}(112) .{ }^{15}$ The transition between the two states is fully reversible: the spectrum shifts back after sample reoxidation in $2 \times 10^{-6} \mathrm{mbar}$ of $\mathrm{O}_{2}$ at $1140 \mathrm{~K}$.

The valence band responds to the thermal treatments in the same way as the core levels. Silica-related features in the valence band shift by the same value $(\sim 0.8 \mathrm{eV})$ as the Si2p and O1s peaks (see the inset of Fig. 2). Annealing did not cause any detectable changes in LEED (not shown) or infrared reflection absorption (IRA) spectroscopy (described later) - or in the large-scale morphology of the films monitored by STM, supporting the treatments' lack of effect on the structure of the silica film.

\section{COMPUTATIONAL RESULTS}

As in our previous studies of thin $\mathrm{SiO}_{2.5}$ films on $\mathrm{Mo}(112),{ }^{9,61}$ several structural models for the $\mathrm{SiO}_{2} / \mathrm{Ru}(0001)$ film were constructed based on the key experimental results: (1) a $(2 \times 2)$ unit cell with respect to the $\mathrm{Ru}(0001)$ substrate $;{ }^{27}$ (2) the hexagonal arrangement of the building units and an $\sim 5.42$ - $\AA$ lattice constant; ${ }^{27}$ (3) one chemical state of $\mathrm{Si}_{\left(\mathrm{Si}^{4+}\right)}$ and two chemical states of $\mathrm{O}$, with the minority of the $\mathrm{O}(\mathrm{Ru})$ species as compared to the $\mathrm{O}(\mathrm{Si})$ species; (4) the absence of $\mathrm{Ru}-\mathrm{O}-\mathrm{Si}$ bonds or Ru surface silicides; and (5) tetrahedral $\left[\mathrm{SiO}_{4}\right]$ coordination. The arrangement of building units and the lattice constant value are similar to those obtained for a $\mathrm{SiO}_{2.5} / \mathrm{Mo}(112)$ film. ${ }^{9}$ The absence of $\mathrm{Ru}-\mathrm{O}-\mathrm{Si}$ and $\mathrm{Ru}-\mathrm{Si}$ bonds suggests that the silica is only weakly bound to the metal surface. Therefore, we choose an unbound, honeycomb-like structure with two layers of corner-sharing $\left[\mathrm{SiO}_{4}\right]$ tetrahedra bonded together by linking oxygen atoms [Fig. 5(a)]. Such a bilayer structure was considered for the $\mathrm{SiO}_{2.5} / \mathrm{Mo}(112)$ film ${ }^{61}$ but was rejected because of a discrepancy with the experimental results.

To investigate the influence of the interfacial oxygen atoms on the structure of the silica films, we consider four additional models containing oxygen adsorbed directly on the $\mathrm{Ru}(0001)$ surface, i.e., at the interface between the silica layer and the metal. These models are based on the well-documented $\mathrm{O} / \mathrm{Ru}(0001)$-ordered structures, such as $p(2 \times 2)-\mathrm{O},{ }^{62}$ $p(2 \times 1)-\mathrm{O},{ }^{43} 3 \mathrm{O}-(2 \times 2),{ }^{63}$ and $(1 \times 1)-\mathrm{O} .{ }^{64}$ To simplify the nomenclature, the O-rich models are denoted by the amount of oxygen within the orthogonal $(2 \times 2) \mathrm{Ru}(0001)$ unit cell, i.e., $\left(\mathrm{SiO}_{2}\right)_{8} 2 \mathrm{O} / \mathrm{Ru},\left(\mathrm{SiO}_{2}\right)_{8} 4 \mathrm{O} / \mathrm{Ru},\left(\mathrm{SiO}_{2}\right)_{8} 6 \mathrm{O} / \mathrm{Ru}$, and $\left(\mathrm{SiO}_{2}\right)_{8} 8 \mathrm{O} / \mathrm{Ru}$, respectively. A systematic search for energy minima was performed for all structures by positioning a silica layer in several distinct registries in relation to the $\mathrm{Ru}(0001)$ surface. The most stable structures of the silica films are shown in Fig. 5. As a result of full valence saturation of both sides of the silica layer, the film stays unbound to the substrate and is separated by $2.75 \AA$ from the topmost $\mathrm{Ru}$ atoms in the $\left(\mathrm{SiO}_{2}\right)_{8} / \mathrm{Ru}$ structure. This separation considerably increases with the increasing number of interfacial oxygen atoms and reaches $3.85 \AA$ for the $\left(\mathrm{SiO}_{2}\right)_{8} 8 \mathrm{O} / \mathrm{Ru}$ structure (cf. Table I). The Si-O bond lengths in all models are in the range between 

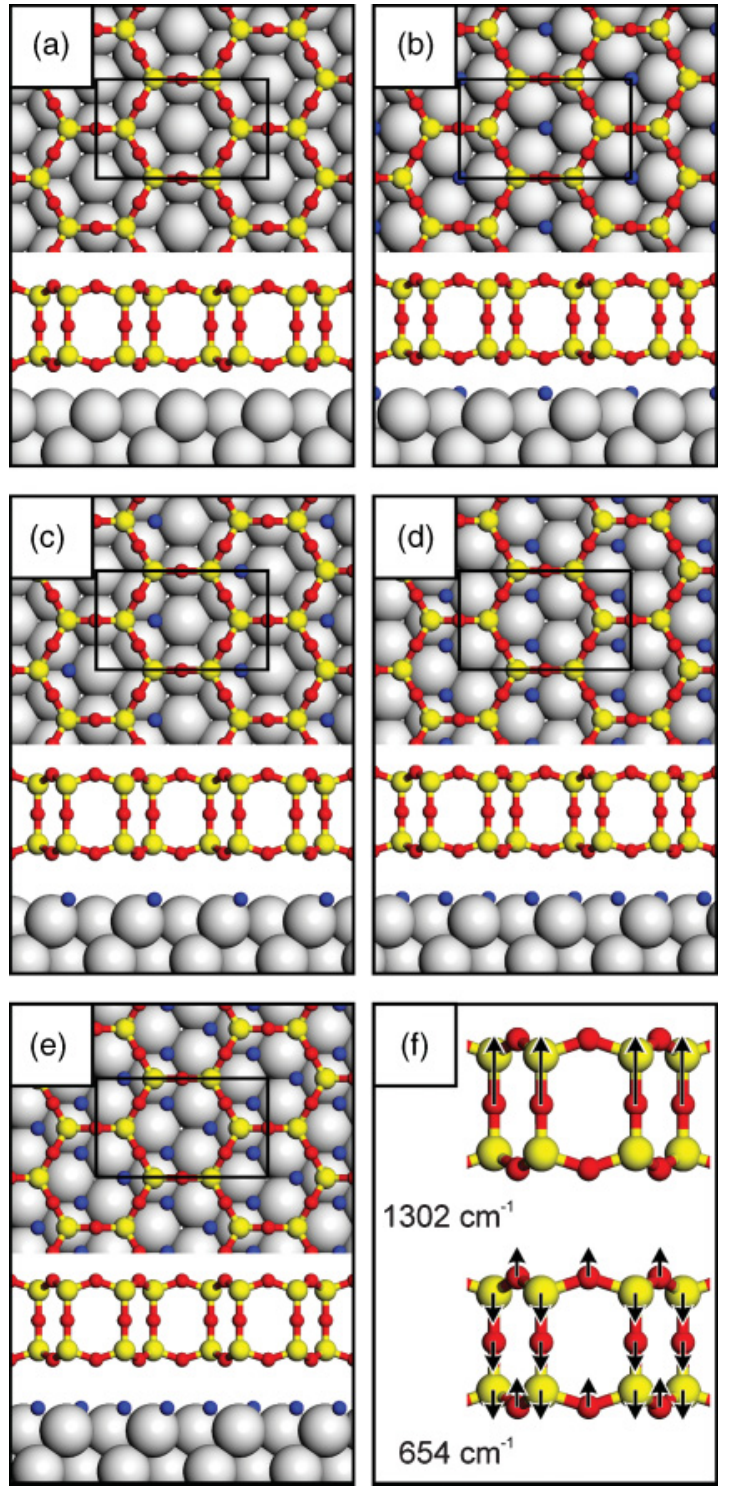

FIG. 5. (Color online) The most stable structure models ( $\mathrm{Si}$ as medium-sized yellow balls, $\mathrm{O}$ as small red or blue balls, and $\mathrm{Ru}$ as large gray balls): (a) $\left(\mathrm{SiO}_{2}\right)_{8} / \mathrm{Ru}$, (b) $\left(\mathrm{SiO}_{2}\right)_{8} 2 \mathrm{O} / \mathrm{Ru}$, (c) $\left(\mathrm{SiO}_{2}\right)_{8} 4 \mathrm{O} / \mathrm{Ru}$, (d) $\left(\mathrm{SiO}_{2}\right)_{8} 6 \mathrm{O} / \mathrm{Ru}$, (e) $\left(\mathrm{SiO}_{2}\right)_{8} 8 \mathrm{O} / \mathrm{Ru}$, and (f) selected normal vibrational modes of the $\left(\mathrm{SiO}_{2}\right)_{8} 2 \mathrm{O} / \mathrm{Ru}$ model. Black-outlined rectangles indicate the orthorhombic $(2 \times 2)$ surface unit cell.

1.62 and $1.65 \AA$ and are not influenced by the number of the interfacial oxygen atoms.

Figure 6 shows the plot of Gibbs free energies of oxygen adsorption [Eq. (1)] for the calculated models as a function of temperature at the oxygen partial pressure $p=2 \times$ $10^{-6}$ mbar (for $\mathrm{O}_{2}$ rotational, vibrational, and translational thermal contributions are included). It demonstrates that the structure with the highest oxygen coverage, $\left(\mathrm{SiO}_{2}\right)_{8} 8 \mathrm{O} / \mathrm{Ru}$, is the most stable up to $\sim 700 \mathrm{~K}$. As the temperature increases, the stability shifts in favor of structures with a smaller amount of interfacial oxygen atoms. The most stable structures are $\left(\mathrm{SiO}_{2}\right)_{8} 6 \mathrm{O} / \mathrm{Ru}$ for temperatures between 700 and $1000 \mathrm{~K}$, $\left(\mathrm{SiO}_{2}\right)_{8} 4 \mathrm{O} / \mathrm{Ru}$ between 1000 and $1100 \mathrm{~K}$, and $\left(\mathrm{SiO}_{2}\right)_{8} 2 \mathrm{O} / \mathrm{Ru}$ between 1100 and $1400 \mathrm{~K}$. The $\mathrm{O}$-poor $\left(\mathrm{SiO}_{2}\right)_{8} / \mathrm{Ru}$ structure
TABLE I. Distances between the silica and the metal surface $d_{z}(\mathrm{O}-\mathrm{Ru})$ (in angstroms), adhesion energies including zero-point energy, $\Delta E_{\mathrm{adh}}$, and dispersion contribution to the adhesion energies, $\Delta E_{\text {adh }}^{d}$ (in $\left.\mathrm{kJ} \cdot \mathrm{mol}^{-1} \cdot \AA^{-2}\right)$ for different $\left(\mathrm{SiO}_{2}\right)_{8} n \mathrm{O} / \mathrm{Ru}$ structure models.

\begin{tabular}{lrrrrr}
\hline$n$ & 0 & 2 & 4 & \multicolumn{1}{c}{6} & \multicolumn{1}{c}{8} \\
\hline$d_{z}(\mathrm{O}-\mathrm{Ru})$ & 2.75 & 3.08 & 3.68 & 3.81 & 3.85 \\
$\Delta E_{\text {adh }}$ & -3.12 & -2.39 & -1.80 & -1.82 & -1.85 \\
$\Delta E_{\text {adh }}^{d}$ & -3.84 & -3.36 & -2.22 & -2.24 & -2.32 \\
\hline \hline
\end{tabular}

is predicted to be stable only above $1400 \mathrm{~K}$. Table I shows the total adhesion energies $\Delta E_{\text {adh }}$ and corresponding dispersion energy contributions $\Delta E^{d}$ adh calculated for the double-layer silica models. For all investigated structures, the pure DFT contribution is repulsive and the final attractive adhesion energies are dominated by the dispersion contribution. The calculated values of $\Delta E_{\text {adh }}$ are similar to those of other dispersion-bound systems, e.g., to the interlayer $\mathrm{BE}$ in bulk $\mathrm{V}_{2} \mathrm{O}_{5} .{ }^{37}$ The $\left(\mathrm{SiO}_{2}\right)_{8} / \mathrm{Ru}$ structure with no interfacial oxygen atoms has the highest adhesion energy. Oxygen adsorption on the $\mathrm{Ru}(0001)$ surface considerably lowers the adhesion energy. Apparently, this effect is connected to the repulsive interaction between the oxygen atoms of the silica film and the interfacial oxygen atoms. Due to this repulsion, adsorption of the same amount of oxygen on an exposed metal surface is preferable to adsorption underneath the silica film (Table II). However, if patches of the silica-covered and the uncovered $\mathrm{Ru}$ surface coexisted (which is not the case for our experiments), equilibrium between the amount of oxygen adsorbed in these two domains, rather than full segregation to the metal domain, would be expected. The reason for this is rapid decrease in BE with increasing oxygen coverage.

Figure 3(b) shows projected O2p local densities of states (DOSs) above the Fermi level probed by NEXAFS spectroscopy. The sharp peak in the region just above the Fermi level originates from DOSs projected on the oxygen atoms bonded to $\mathrm{Ru}$ and is not present for the $\left(\mathrm{SiO}_{2}\right)_{8} / \mathrm{Ru}$ structure.

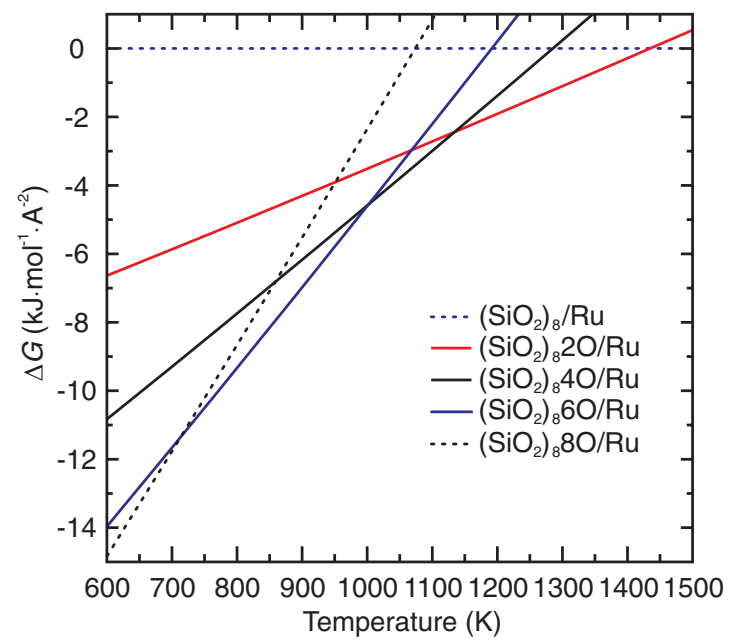

FIG. 6. (Color online) Gibbs free energy of oxygen adsorption $\Delta G\left(T, p=2 \times 10^{-6}\right.$ mbar $)$ as a function of temperature for the double-layer silica models. 
TABLE II. Average BEs of an $\mathrm{O}$ atom (in electron volts, including zero-point energy) for different $\left(\mathrm{SiO}_{2}\right)_{8} n \mathrm{O} / \mathrm{Ru}$ and $n \mathrm{O} / \mathrm{Ru}$ structure models. Energies are given with respect to molecular oxygen.

\begin{tabular}{lcccc}
\hline \hline$n$ & 2 & 4 & 6 & 8 \\
\hline$\left(\mathrm{SiO}_{2}\right)_{8} n \mathrm{O} / \mathrm{Ru}$ & 2.84 & 2.52 & 2.32 & 2.07 \\
$n \mathrm{O} / \mathrm{Ru}$ & 3.03 & 2.69 & 2.43 & 2.15 \\
\hline \hline
\end{tabular}

The broad band between 5 and $15 \mathrm{eV}$ above the Fermi level corresponds to the states localized on the $\mathrm{O}$ atoms in the silica film. The amount of interfacial oxygen only slightly influences the position of the broad band but strongly affects the intensity ratio of the broad band with respect to the sharp peak.

Figure 7 shows the calculated harmonic IRA spectra. For all structure models, only two IR active modes above $600 \mathrm{~cm}^{-1}$ are observed. The most intense mode $\sim 1300 \mathrm{~cm}^{-1}$ originates from the in-phase combination of asymmetric stretching vibrations of the interlayer Si-O-Si linkages, while the second mode $\sim 650 \mathrm{~cm}^{-1}$ involves coupled symmetric stretching and bending vibrations of $\mathrm{Si}-\mathrm{O}-\mathrm{Si}$ intralayer bonds as shown in Fig. 5(f).

Figure 8 shows calculated $\mathrm{BE}$ shifts of the $\mathrm{O} 1 \mathrm{~s}$ core levels. In all structures, the BEs of the different oxygen atoms in the silica film vary by less than $0.13 \mathrm{eV}$ and therefore are hardy distinguishable in the experimental XP spectra. The differences of BEs between $\mathrm{O}$ atoms adsorbed directly on the metal surface and $\mathrm{O}$ atoms in the silica layer are much larger and change with the increasing oxygen content: 2.5, 2.2, 2.0, and $1.8 \mathrm{eV}$ for the $\left(\mathrm{SiO}_{2}\right)_{8} 2 \mathrm{O} / \mathrm{Ru}$, $\left(\mathrm{SiO}_{2}\right)_{8} 4 \mathrm{O} / \mathrm{Ru},\left(\mathrm{SiO}_{2}\right)_{8} 6 \mathrm{O} / \mathrm{Ru}$, and $\left(\mathrm{SiO}_{2}\right)_{8} 8 \mathrm{O} / \mathrm{Ru}$ models, respectively. To understand the origin of this change, ad-

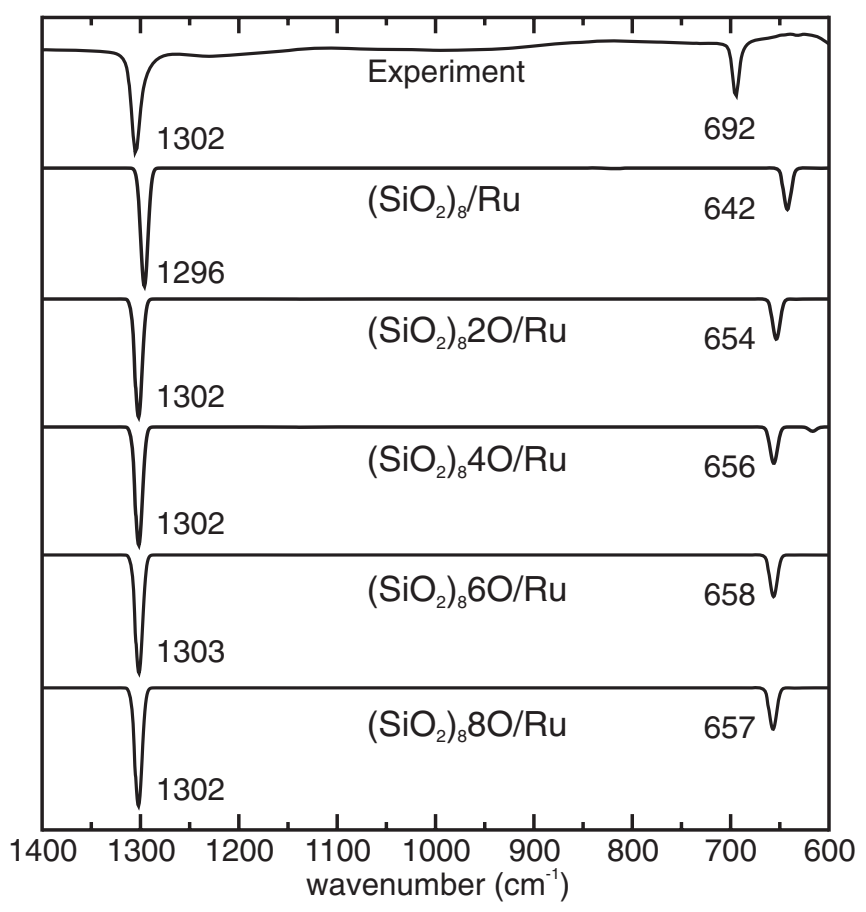

FIG. 7. Experimental IRA spectrum of O-rich silica film grown on $\mathrm{Ru}(0001)$ compared with spectra simulated for the model systems. Computed frequencies are scaled by a factor of 1.0341 .
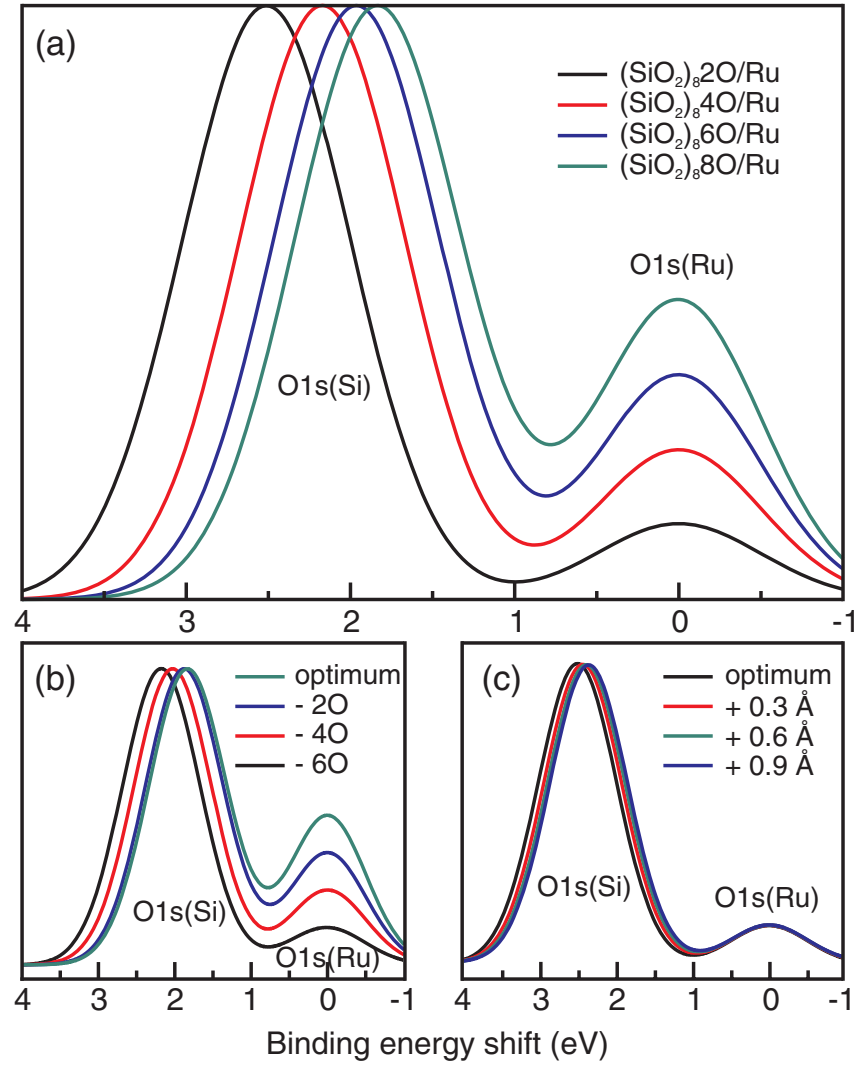

FIG. 8. (Color online) Simulated shape of XP spectra for (a) the most stable double-layer $\left(\mathrm{SiO}_{2}\right)_{8} n \mathrm{O} / \mathrm{Ru}$ models, (b) modified $\left(\mathrm{SiO}_{2}\right)_{8} 8 \mathrm{O} / \mathrm{Ru}$ model (see text for details), and (c) modified $\left(\mathrm{SiO}_{2}\right)_{8} 2 \mathrm{O} / \mathrm{Ru}$ model (see text for details). The shift of BEs is given with respect to the $\mathrm{O} 1 \mathrm{~s}(\mathrm{Ru})$ peak. Attenuation is not included.

ditional single-point $\mathrm{BEs}$ calculations were performed for modified $\left(\mathrm{SiO}_{2}\right)_{8} 2 \mathrm{O} / \mathrm{Ru}$ and $\left(\mathrm{SiO}_{2}\right)_{8} 8 \mathrm{O} / \mathrm{Ru}$ structures. First, the interfacial oxygen atoms were removed pair by pair from the relaxed $\left(\mathrm{SiO}_{2}\right)_{8} 8 \mathrm{O} / \mathrm{Ru}$ structure, keeping all atomic positions constant. Second, the distance between the silica layer and the metal surface was varied in the $\left(\mathrm{SiO}_{2}\right)_{8} 2 \mathrm{O} / \mathrm{Ru}$ structure, keeping all remaining internal coordinates frozen. These results are shown in Figs. 8(b) and 8(c), respectively. on of the results clearly shows that the progression in the BEs shifts is related to the change of electronic properties of the metal substrate induced by $\mathrm{O}$ adsorption [Fig. 8(b)] and is virtually independent of the distance between the silica film and the metal substrate [Fig. 8(c)].

\section{COMPARISON: EXPERIMENT VERSUS THEORY}

Figure 4 shows experimental XP spectra obtained for the silica film stepwise annealed in UHV from 1030 to $1150 \mathrm{~K}$. Energy separation between the $\mathrm{O}(\mathrm{Si})$ and the $\mathrm{O}(\mathrm{Ru})$ peaks for the as-prepared films is $2.0 \mathrm{eV}$, and it changes upon annealing in UHV to $2.1 \mathrm{eV}(1030 \mathrm{~K}), 2.3 \mathrm{eV}(1080 \mathrm{~K})$, $2.4 \mathrm{eV}(1130 \mathrm{~K})$, and $2.5 \mathrm{eV}(1150 \mathrm{~K})$. The DFT calculations, combined with thermodynamic analysis, revealed that the amount of interfacial oxygen adsorbed on the Ru substrate depends on the annealing temperature. As shown in Fig. 6, the $\left(\mathrm{SiO}_{2}\right)_{8} 6 \mathrm{O} / \mathrm{Ru}$ structure is the most stable at $\sim 900 \mathrm{~K}$, but it 
transforms into $\left(\mathrm{SiO}_{2}\right)_{8} 4 \mathrm{O} / \mathrm{Ru}$ and finally into $\left(\mathrm{SiO}_{2}\right)_{8} 2 \mathrm{O} / \mathrm{Ru}$ upon increasing temperature. The O-poor $\left(\mathrm{SiO}_{2}\right)_{8} / \mathrm{Ru}$ structure dominates the surface only above $1400 \mathrm{~K}$. XP-spectra simulations performed for these structures [Fig. 8(a)] yield values comparable to those obtained in experiments, i.e., 1.8 $\mathrm{eV}$ for $\left(\mathrm{SiO}_{2}\right)_{8} 8 \mathrm{O} / \mathrm{Ru}, 2.0 \mathrm{eV}$ for $\left(\mathrm{SiO}_{2}\right)_{8} 6 \mathrm{O} / \mathrm{Ru}, 2.2 \mathrm{eV}$ for $\left(\mathrm{SiO}_{2}\right)_{8} 4 \mathrm{O} / \mathrm{Ru}$, and $2.5 \mathrm{eV}$ for $\left(\mathrm{SiO}_{2}\right)_{8} 2 \mathrm{O} / \mathrm{Ru}$ structures. These results demonstrate that annealing of the as-prepared films at elevated temperatures leads to gradual desorption of oxygen from the metal surface. This process, in turn, results in an increase of the energy separation between the $\mathrm{O} 1 \mathrm{~s}(\mathrm{Si})$ and the $\mathrm{O} 1 \mathrm{~s}(\mathrm{Ru})$ levels observed in both experiments (Fig. 4) and calculations [Fig. 8(a)].

The projected $\mathrm{O} 2 \mathrm{p}$ density of unoccupied states calculated for the models matches well the NEXAFS spectrum, as shown in Fig. 3. According to the calculations, the well-resolved state $\sim 2 \mathrm{eV}$ above the Fermi level, revealed in the experiment, is only present when the structure contains interfacial oxygen. The relative intensity of the two spectral features (i.e., a sharp band at $2 \mathrm{eV}$ and a broad band between 5 and $15 \mathrm{eV}$ ) suggests that the as-prepared (i.e., prepared in oxygen ambient) film contains on average between two and four interfacial $\mathrm{O}$ atoms per unit cell. These observations are consistent with stability analysis, indicating that the $\left(\mathrm{SiO}_{2}\right)_{8} 2 \mathrm{O} / \mathrm{Ru}$ and $\left(\mathrm{SiO}_{2}\right)_{8} 4 \mathrm{O} / \mathrm{Ru}$ structures are the most stable under the experimental conditions applied.

The O-rich and O-poor films can hardly be distinguished by IRAS. Only small variations of the vibrational frequencies with oxygen content at the interface are observed (not shown here). The experimental IRA spectra of the silica films show two very sharp absorption bands at 1302 and $692 \mathrm{~cm}^{-1}$. For all investigated models, the positions and relative intensities of the calculated bands are in excellent agreement with the experimental results (Fig. 7).

\section{CONCLUSIONS}

Through a combination of DFT calculations and electron spectroscopy results, we provide new insights into the atomistic picture of ultrathin silica films grown on $\mathrm{Ru}(0001)$. The silica film features an all-Si silicate sheet formed by corner-sharing $\left[\mathrm{SiO}_{4}\right]$ tetrahedra and is weakly bound to a $\mathrm{Ru}(0001)$ substrate, thus allowing oxygen atoms to reversibly adsorb directly on the metal surface underneath the film. The amount of adsorbed oxygen can be reversibly varied by vacuum annealing and oxidation, which in turn result in the gradual changes of the silica/Ru electronic states. This finding opens the possibility of tuning electronic properties of oxide/metal systems without altering the thickness and structure of an oxide overlayer.

\section{ACKNOWLEDGEMENT}

Financial support by Deutsche Forschungsgemeinschaft within Sonderforschungsbereich 546 and the Cluster of Excellence "Unifying Concepts in Catalysis," as well as by Fonds der Chemischen Industrie, is gratefully acknowledged.
*Present address: Institut für Materialwissenschaft und Werkstofftechnologie, Friedrich-Schiller-Universität Jena, Löbdergraben 32, D-07743 Jena, Germany; marek.sierka@uni-jena.de

†shaikhutdinov@fhi-berlin.mpg.de

${ }^{1}$ G. Pacchioni, L. Giordano, and M. Baistrocchi, Phys. Rev. Lett. 94, 226104 (2005).

${ }^{2}$ D. Ricci, A. Bongiorno, G. Pacchioni, and U. Landman, Phys. Rev. Lett. 97, 036106 (2006).

${ }^{3}$ M. Kulawik, N. Nilius, and H.-J. Freund, Phys. Rev. Lett. 96, 036103 (2006).

${ }^{4}$ M. Sterrer, T. Risse, M. Heyde, H. P. Rust, and H.-J. Freund, Phys. Rev. Lett. 98, 206103 (2007).

${ }^{5}$ H.-J. Freund and G. Pacchioni, Chem. Soc. Rev. 37, 2224 (2008).

${ }^{6}$ Q.-H. Wua, A. Fortunelli, and G. Granozzic, Int. Rev. Phys. Chem. 28, 517 (2009).

${ }^{7}$ H.-J. Freund, Surf. Sci. 601, 1438 (2007).

${ }^{8}$ M. Sierka, Prog. Surf. Sci. 85, 398 (2010).

${ }^{9}$ J. Goniakowski and C. Noguera, Interface Sci. 12, 93 (2004).

${ }^{10}$ L. Giordano, F. Cinquini, and G. Pacchioni, Phys. Rev. B 73, 045414 (2006).

${ }^{11}$ S. Prada, U. Martinez, and G. Pacchioni, Phys. Rev. B 78, 235423 (2008).

${ }^{12}$ U. Martinez, J.-F. Jerratsch, N. Nilius, L. Giordano, G. Pacchioni, and H.-J. Freund, Phys. Rev. Lett. 103, 056801 (2009).

${ }^{13}$ J. Weissenrieder, S. Kaya, J.-L. Lu, H.-J. Gao, S. Shaikhutdinov, H.-J. Freund, M. M. Sierka, T. K. Todorova, and J. Sauer, Phys. Rev. Lett. 95, 076103 (2005).
${ }^{14}$ G. Kresse, M. Schmid, E. Napetschnig, M. Shishkin, L. Köhler, and P. Varga, Science 308, 1440 (2005).

${ }^{15}$ M. Sierka, T. K. Todorova, S. Kaya, D. Stacchiola, J. Weissenrieder, J. Lu, H. Gao, S. Shaikhutdinov, H.-J. Freund, and J. Sauer, Chem. Phys. Lett. 424, 115 (2006).

${ }^{16}$ S. Surnev, L. Vitali, M. G. Ramsey, F. P. Netzer, G. Kresse, and J. Hafner, Phys. Rev. B 61, 13945 (2000).

${ }^{17}$ P. Yang, M. Ando, and N. Murase, J. Colloid Interface Sci. 354, 455 (2011).

${ }^{18}$ S. A. El-Safty, A. Shahat, M. Mekawy, H. Nguyen, W. Warkocki, and M. Ohnuma, Nanotechnology 21, 375603 (2010).

${ }^{19}$ M. Kundu and Y. Murata, Appl. Phys. Lett. 80, 1921 (2002).

${ }^{20}$ Z. Zhang, Z. Jinag, Y. Yao, D. Tan, Q. Fu, and X. Bao, Thin Solid Films 516, 3741 (2008).

${ }^{21}$ A. Sasahara, C. L. Pang, and M. Tomitori, J. Phys. Chem. C 114, 20189 (2010).

${ }^{22}$ T. Schroeder, M. Adelt, B. Richter, M. Naschitzki, M. Bäumer, and H.-J. Freund, Surf. Rev. Lett. 7, 7 (2000).

${ }^{23}$ L. Giordano, D. Ricci, G. Pacchioni, and P. Ugliengo, Surf. Sci. 584, 225 (2005).

${ }^{24}$ S. Kaya, M. Baron, D. Stacchiola, J. Weissenrieder, S. Shaikhutdinov, T. K. Todorova, M. Sierka, J. Sauer, and H.-J. Freund, Surf. Sci. 601, 4849 (2007).

${ }^{25}$ M. S. Chen and D. W. Goodman, J. Phys. Condens. Matter 20, 264013 (2008)

${ }^{26}$ J. Seifert, A. Schüller, H. Winter, R. Włodarczyk, J. Sauer, and M. Sierka, Phys. Rev. B 82, 035436 (2010). 
${ }^{27}$ D. Löffler, J. J. Uhlrich, M. Baron, B. Yang, X. Yu, L. Lichtenstein, L. Heinke, C. Büchner, M. Heyde, S. Shaikhutdinov, H.-J. Freund, R. Włodarczyk, M. Sierka, and J. Sauer, Phys. Rev. Lett. 105, 146104 (2010).

${ }^{28}$ F. Liebau, Structural Chemistry of Silicates (Springer, Berlin, 1985).

${ }^{29}$ G. Kresse and J. Furthmüller, Comp. Mat. Sci. 6, 15 (1996).

${ }^{30}$ G. Kresse and J. Furthmüller, Phys. Rev. B 54, 11169 (1996).

${ }^{31}$ J. P. Perdew, K. Burke, and M. Ernzerhof, Phys. Rev. Lett. 77, 3865 (1996).

${ }^{32}$ J. P. Perdew, K. Burke, and M. Ernzerhof, Phys. Rev. Lett. 78, 1396 (1997).

${ }^{33}$ P. E. Blöchl, Phys. Rev. B 50, 17953 (1994).

${ }^{34}$ G. Kresse and D. Joubert, Phys. Rev. B 59, 1758 (1999).

${ }^{35}$ See Supplemental Material at http://link.aps.org/supplemental/ 10.1103/PhysRevB.85.085403 for parameters related to the description of dispersion forces.

${ }^{36}$ S. Grimme, J. Comp. Chem. 27, 1787 (2006).

${ }^{37}$ T. Kerber, M. Sierka, and J. Sauer, J. Comp. Chem. 29, 2088 (2008).

${ }^{38}$ H. J. Monkhorst and J. D. Pack, Phys. Rev. B 13, 5188 (1976).

${ }^{39}$ L. Köhler and G. Kresse, Phys. Rev. B 70, 165405 (2004).

${ }^{40}$ R. K. Sato and P. F. McMillan, J. Phys. Chem. 91, 3494 (1987).

${ }^{41}$ J. F. Scott and S. P. S. Porto, Phys. Rev. 161, 903 (1967).

${ }^{42}$ A. V. Morozkin and Y. D. Seropegin, J. Alloys Compd. 365, 168 (2004).

${ }^{43}$ H. Pfnür, G. Held, M. Lindroos, and D. Menzel, Surf. Sci. 220, 43 (1989).

${ }^{44}$ A. Männig, Z. Zhao, D. Rosenthal, K. Christmann, H. Hoster, H. Rauscher, and R. J. Behm, Surf. Sci. 576, 29 (2005).

${ }^{45}$ F. J. Grunthaner, P. J. Grunthaner, R. P. Vasquez, B. F. Lewis, J. Maserjian, and A. Madhukar, J. Vac. Sci. Technol. 16, 1443 (1979).

${ }^{46}$ W. Braun and H. Kuhlenbeck, Surf. Sci. 180, 279 (1987).
${ }^{47}$ F. Rochet, Ch. Poncey, G. Dufour, H. Roulet, C. Guillot, and F. Sirotti, J. Non-Cryst. Solid. 216, 148 (1997).

${ }^{48}$ A. Böttcher and H. Niehus, Phys. Rev. B 60, 14396 (1999).

${ }^{49}$ R. Blume, H. Niehus, H. Conrad, and A. Böttcher, J. Phys. Chem. B 108, 14332 (2004).

${ }^{50}$ R. Blume, W. Christen, and H. Niehus, J. Phys. Chem. B 110, 13912 (2006).

${ }^{51}$ T. Schroeder, J. B. Giorgi, M. Bäumer, and H.-J. Freund, Phys. Rev. B 66, 165422 (2002).

${ }^{52}$ A. Di Pomponio, A. Continenza, L. Lozzi, M. Passacantando, S. Santucci, and P. Picozzi, Solid State Comm. 95, 313 (1995).

${ }^{53}$ S. Wendt, E. Ozensoy, T. Wei, M. Frerichs, Y. Cai, M. S. Chen, and D. W. Goodman, Phys. Rev. B 72, 115409 (2005).

${ }^{54}$ T. H. DiStefano and D. E. Eastman, Phys. Rev. Lett. 27, 1560 (1971).

${ }^{55}$ B. Fischer, R. A. Pollak, T. H. DiStefano, and W. D. Grobman, Phys. Rev. B 15, 3193 (1977).

${ }^{56}$ J. G. Chen, Surf. Sci. Rep. 30, 1 (1997).

${ }^{57}$ S.-D. Mo and W. Y. Ching, Appl. Phys. Lett. 78, 3809 (2001).

${ }^{58}$ A. V. Soldatov, M. Kasrai, and G. M. Bancroft, Solid State Comm. 115, 687 (2000).

${ }^{59}$ A. Böttcher and H. Niehus, J. Chem. Phys. 110, 3186 (1999).

${ }^{60}$ J. H. Kim, J. H. Lee, H. Kato, N. Horimoto, M. Kawai, and Y. S. Lee, J. Korean Phys. Soc. 42, 408 (2003).

${ }^{61}$ T. K. Todorova, M. Sierka, J. Sauer, S. Kaya, J. Weissenrieder, J.-L. Lu, H.-J. Gao, S. Shaikhutdinov, and H.-J. Freund, Phys. Rev. B 73, 165414 (2006).

${ }^{62}$ M. Lindroos, H. Pfnür, G. Held, and D. Menzel, Surf. Sci. 222, 451 (1989).

${ }^{63}$ K. L. Kostov, M. Gsell, P. Jakob, T. Moritz, W. Widdra, and D. Menzel, Surf. Sci. 394, L138 (1997).

${ }^{64}$ C. Stampfl, S. Schwegmann, H. Over, M. Scheffler, and G. Ertl, Phys. Rev. Lett. 77, 3371 (1996). 